\title{
Endoscopic mucosal biopsies are useful in distinguishing granulomatous colitis due to Crohn's disease from tuberculosis
}

\author{
A B Pulimood, B S Ramakrishna, G Kurian, S Peter, S Patra, V I Mathan, M M Mathan
}

\begin{abstract}
Background-Intestinal tuberculosis and Crohn's disease are chronic granulomatous disorders that are difficult to differentiate histologically.

Aims-To characterise distinctive diagnostic features of tuberculosis and Crohn's disease in mucosal biopsy specimens obtained at colonoscopy.

Methods-Selected histological parameters were evaluated retrospectively in a total of 61 biopsy sites from 20 patients with tuberculosis and 112 biopsy sites from 20 patients with Crohn's disease. The patients were chosen on the basis of clinical history, colonoscopic findings, diagnostic histology, and response to treatment.

Results-The histological parameters characteristic of tuberculosis were multiple (mean number of granulomas per section: 5.35), large (mean widest diameter: $193 \mu \mathrm{m})$, confluent granulomas often with caseating necrosis. Other features were ulcers lined by conglomerate epithelioid histiocytes and disproportionate submucosal inflammation. The features characteristic of Crohn's disease were infrequent (mean number of granulomas per section: 0.75), small (mean widest diameter: 95 $\mu \mathrm{m})$ granulomas, microgranulomas (defined as poorly organised collections of epithelioid histiocytes), focally enhanced colitis, and a high prevalence of chronic inflammation, even in endoscopically normal appearing areas.

Conclusions-The type and frequency of granulomas, presence or absence of ulcers lined by epithelioid histiocytes and microgranulomas, and the distribution of chronic inflammation have been identified as histological parameters that can be used to differentiate tuberculosis and Crohn's disease in mucosal biopsy specimens obtained at colonoscopy.

(Gut 1999;45:537-541)
\end{abstract}

Keywords: tuberculosis; Crohn's disease; mucosal biopsy; histology

In geographical regions where both Crohn's colitis and tuberculosis are prevalent, the differential diagnosis of granulomatous ileocolitis poses a challenge. The ultimate natural history of the two diseases is different. Appropriate antituberculous treatment leads in most cases of tuberculous ileocolitis (TEC) to com- plete cure, whereas Crohn's disease is a progressive relapsing illness unaffected by antituberculous treatment. Endoscopic mucosal biopsy specimens obtained through fibreoptic sigmoidoscopes or colonoscopes from the rectum, different areas of the colon, the ileocaecal valve, and terminal ileum provide the possibility of histological confirmation of the diagnosis of TEC or Crohn's disease even in suspected early cases. Caseating granulomas and acid fast bacilli, diagnostic of tuberculosis are, however, present only in a small proportion of patients, ${ }^{1-5}$ and several histological parameters considered characteristic of Crohn's disease such as discontinuous chronic inflammation, ${ }^{6-9}$ focal lesions, ${ }^{9-13}$ and microgranulomas ${ }^{14}{ }^{15}$ have not been evaluated in biopsy specimens from patients with tuberculosis.

Granulomatous inflammation of the terminal ileum, caecum, colon, and rectum due to Mycobacterium tuberculosis (TEC) has a high prevalence in southern India. During the last decade, an increasing number of patients have also been diagnosed as having Crohn's ileocolitis, based on the clinical features, radiological changes, colonoscopic findings, and, where tissues were available at endoscopy, on histological appearance. Where appropriate, patients with an uncertain diagnosis were given antituberculous therapy and a final diagnosis made on the basis of response to the treatment. This study was designed to evaluate a variety of histological criteria described in patients with TEC or Crohn's disease of the colon and to identify potential histological patterns useful in establishing the diagnosis by endoscopic biopsy.

\section{Materials and methods}

Twenty patients each, in whom the diagnosis of Crohn's disease or TEC of the ileum or colon had been made in the 10 year period 1986-1996 and who had undergone endoscopic evaluation and biopsy at their first visit were selected out of a total of 81 cases of Crohn's disease and 138 cases of TEC. All the clinical records as well as histological material were reviewed by a senior gastroenterologist and a senior gastrointestinal pathologist and the diagnosis reconfirmed on the basis of well established clinical, endoscopic, radiological, and histological parameters. In two cases, the clinical course of the patient and response to

Abbreviations used in this paper: TEC, tuberculous ileocolitis. 
Table 1 Prevalence and characteristics of selected histological parameters in patients with tuberculous (TB) and Crohn's (CD) colitis

\begin{tabular}{|c|c|c|c|c|c|c|c|c|c|c|c|c|}
\hline \multirow[b]{2}{*}{ Parameters } & \multicolumn{3}{|c|}{ All patients } & \multicolumn{3}{|c|}{ All biopsy specimens } & \multicolumn{3}{|c|}{$\begin{array}{l}\text { Endoscopically abnormal } \\
\text { mucosa }\end{array}$} & \multicolumn{3}{|c|}{$\begin{array}{l}\text { Endoscopically normal } \\
\text { mucosa }\end{array}$} \\
\hline & $\begin{array}{l}T B \\
(n=20)\end{array}$ & $\begin{array}{l}C D \\
(n=20)\end{array}$ & $p$ Value & $\begin{array}{c}T B \\
(n=61)\end{array}$ & $\begin{array}{c}C D \\
(n=112)\end{array}$ & $p$ Value & $\begin{array}{c}T B \\
(n=43)\end{array}$ & $\begin{array}{c}C D \\
(n=49)\end{array}$ & $p$ Value & $\begin{array}{c}T B \\
(n=18)\end{array}$ & $\begin{array}{c}C D \\
(n=63)\end{array}$ & $p$ Value \\
\hline Granulomas & $100 \%$ & $55 \%$ & $0.0006^{\star}$ & $46 \%$ & $14 \%$ & $0.0000^{\star}$ & $63 \%$ & $27 \%$ & $0.0004^{\star}$ & $5 \%$ & $5 \%$ & 1.0000 \\
\hline Average size of granulomas $(\mu \mathrm{m})$ & 193 & 95 & $0.0001^{\star}$ & 204.94 & 102.08 & $0.0001^{\star}$ & 207.90 & 101.63 & $0.0003^{\star}$ & 125.00 & 104.17 & 0.6547 \\
\hline Granuloma $>200 \mu \mathrm{m}$ & $90 \%$ & $5 \%$ & $0.0000^{\star}$ & $33 \%$ & $1 \%$ & $0.0000^{\star}$ & $47 \%$ & $2 \%$ & $0.0000^{\star}$ & $0 \%$ & $0 \%$ & \\
\hline Average no of granulomas/section & 5.35 & 0.75 & $0.0007^{\star}$ & 4.82 & 1.44 & $0.0025^{\star}$ & 4.96 & 1.54 & $0.0066^{\star}$ & 1 & 1 & 1.0000 \\
\hline$>5$ granulomas/section & $40 \%$ & $0 \%$ & $0.0016^{\star}$ & $18 \%$ & $0 \%$ & $0.0000^{\star}$ & $26 \%$ & $0 \%$ & $0.0002^{\star}$ & $0 \%$ & $0 \%$ & \\
\hline Caseation & $40 \%$ & $0 \%$ & $0.0016^{\star}$ & $13 \%$ & $0 \%$ & $0.0002^{\star}$ & $19 \%$ & $0 \%$ & $0.0015^{\star}$ & $0 \%$ & $0 \%$ & \\
\hline Confluence & $60 \%$ & $0 \%$ & 0.0000 & $15 \%$ & $0 \%$ & $0.0001^{\star}$ & $21 \%$ & $0 \%$ & $0.0006^{\star}$ & $0 \%$ & $0 \%$ & \\
\hline \multicolumn{13}{|l|}{ Location of granuloma } \\
\hline Mucosa & $70 \%$ & $50 \%$ & 0.1967 & $23 \%$ & $13 \%$ & 0.0745 & $33 \%$ & $22 \%$ & 0.2768 & $5 \%$ & $5 \%$ & 1.0000 \\
\hline Submucosa & $45 \%$ & $5 \%$ & $0.0034^{\star}$ & $18 \%$ & $6 \%$ & $0.0000^{\star}$ & $25 \%$ & $2 \%$ & $0.0008^{\star}$ & $0 \%$ & $0 \%$ & \\
\hline Granulation tissue & $50 \%$ & $15 \%$ & $0.0181^{\star}$ & $23 \%$ & $2 \%$ & $0.0000^{\star}$ & $33 \%$ & $4 \%$ & $0.0003^{\star}$ & $0 \%$ & $0 \%$ & \\
\hline Microgranulomas & $5 \%$ & $40 \%$ & $0.0098^{\star}$ & $2 \%$ & $9 \%$ & 0.0528 & $2 \%$ & $8 \%$ & 0.2240 & $0 \%$ & $10 \%$ & 0.2093 \\
\hline Ulcers & $75 \%$ & $65 \%$ & 0.4901 & $44 \%$ & $15 \%$ & $0.0000^{\star}$ & $60 \%$ & $33 \%$ & $0.0075^{\star}$ & $5 \%$ & $2 \%$ & 0.3972 \\
\hline Aphthous & $5 \%$ & $5 \%$ & 0.2435 & $2 \%$ & $1 \%$ & 0.5822 & $2 \%$ & $0 \%$ & 0.4673 & $0 \%$ & $2 \%$ & 0.7777 \\
\hline Deep & $80 \%$ & $50 \%$ & $0.0467^{\star}$ & $41 \%$ & $11 \%$ & $0.0000^{\star}$ & $58 \%$ & $24 \%$ & $0.0010^{\star}$ & $0 \%$ & $0 \%$ & \\
\hline With epithelioid histiocytes & $45 \%$ & $5 \%$ & $0.0034^{\star}$ & $15 \%$ & $2 \%$ & $0.0000^{\star}$ & $21 \%$ & $2 \%$ & $0.0040^{\star}$ & $0 \%$ & $0 \%$ & \\
\hline Architectural alteration & $65 \%$ & $75 \%$ & $0.4901^{\star}$ & $41 \%$ & $40 \%$ & 0.9179 & $53 \%$ & $57 \%$ & 0.7249 & $11 \%$ & $30 \%$ & 0.1371 \\
\hline Chronic inflammation & $90 \%$ & $90 \%$ & 0.6975 & $51 \%$ & $75 \%$ & $0.0012^{\star}$ & $67 \%$ & $80 \%$ & 0.1854 & $11 \%$ & $71 \%$ & $0.0000^{\star}$ \\
\hline Discontinuous inflammation & $50 \%$ & $50 \%$ & 1.0000 & $23 \%$ & $19 \%$ & 0.5110 & $30 \%$ & $31 \%$ & 0.9685 & $5 \%$ & $10 \%$ & 0.5108 \\
\hline Focally enhanced colitis & $20 \%$ & $50 \%$ & $0.0467^{\star}$ & $7 \%$ & $14 \%$ & 0.1287 & $9 \%$ & $24 \%$ & 0.0551 & $0 \%$ & $6 \%$ & 0.3580 \\
\hline $\begin{array}{l}\text { Disproportionate submucosal } \\
\text { inflammation }\end{array}$ & $65 \%$ & $5 \%$ & $0.0001^{\star}$ & $25 \%$ & $2 \%$ & $0.0000^{\star}$ & $35 \%$ & $2 \%$ & 0.0000 & $0 \%$ & $0 \%$ & \\
\hline
\end{tabular}

${ }^{\star} \mathrm{p}<0.05$.

antituberculous treatment was particularly useful in confirming the final diagnosis. Nine of the patients with tuberculosis were included in a previous report from our department on the colonoscopic diagnosis of tuberculosis. ${ }^{16}$

Colonoscopy had been carried out in all patients with an Olympus fibreoptic colonoscope under sedation, after appropriate preparation. Areas of abnormality of the mucosa had been noted and an average of five to six biopsy specimens from each abnormal appearing area


Figure 1 (A) Colonic mucosal biopsy of a patient with tuberculosis showing multiple, large, confluent granulomas (maximum diameter of largest granuloma: $438 \mu \mathrm{m}$ ). (B) Colonic mucosal biopsy of a patient with Crohn's disease showing a single, small, naked granuloma in the mucosa (maximum diameter: $65 \mu \mathrm{m}$ ). and two large specimens from suitable normal appearing areas had been obtained. A total of 43 specimens had been obtained from endoscopically abnormal mucosa from the 20 patients with tuberculosis (seven from the ileum, 11 from the caecum, 13 from the ascending colon, three from the transverse colon, three from the descending colon, two from the sigmoid colon, and four from the rectum), and 49 specimens from the 20 patients with Crohn's disease (12 from the ileum, 10 from the caecum, nine from the ascending colon, four from the transverse colon, four from the descending colon, three from the sigmoid colon, and seven from the rectum). Eighteen biopsy specimens were obtained from apparently normal mucosa in the tuberculosis patients (none from the ileum, one from the caecum, one from the ascending colon, three from the transverse colon, four from the descending colon, two from the sigmoid colon, and seven from the rectum) and 63 from patients with Crohn's disease (six from the ileum, eight from the caecum, six from the ascending colon, 13 from the transverse colon, five from the descending colon, 12 from the sigmoid, and 13 from the rectum).

Biopsy specimens, fixed in formaldehyde and embedded in paraffin wax, had been serially sectioned with a minimum of 12 sections from each specimen. They were examined by a pathologist with no prior knowledge of the final diagnosis. The following parameters were evaluated.

Granulomas were defined as round or oval, organised collections of epithelioid histiocytes along with Langhans giant cells, lymphocytes, and occasionally neutrophil polymorphs. The size of the granulomas (maximum diameter), the number of granulomas per section, caseation and confluence of granulomas, the presence of a lymphoid cuff, and the location of the granulomas were noted. 


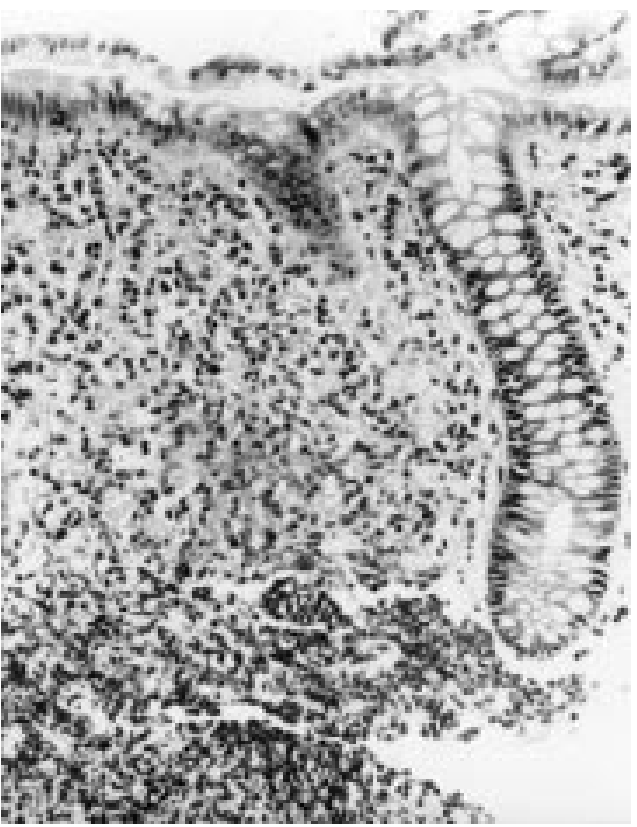

Figure 2 Colonic mucosa of a patient with Crohn's disease, showing an ill formed microgranuloma over a lymphoid follicle (maximum diameter: $75 \mu \mathrm{m}$ ).

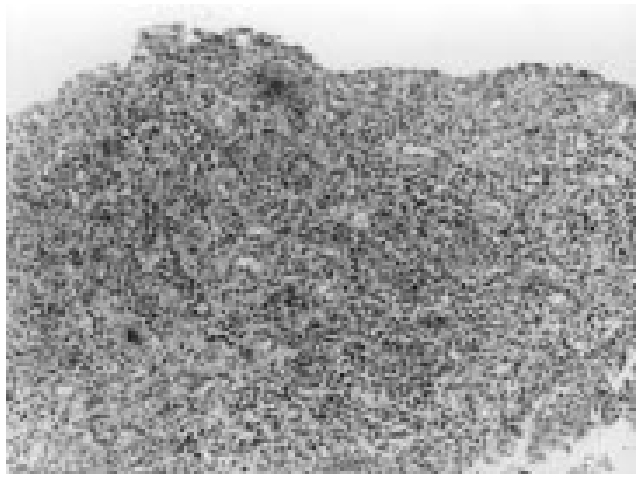

Figure 3 Mucosal biopsy specimen from a patient with Crohn's disease, showing inflammatory granulation tissue from a site of deep ulceration.

Microgranulomas were defined as small, poorly organised collections of epithelioid cells without the other features of granulomas. ${ }^{10}$

ULCERATION

Aphthous ulcers were defined as superficial erosions of the epithelium. When the mucosa was replaced by granulation tissue, a deep ulcer was recorded. In some deep ulcers, a band of conglomerate epithelioid histiocytes with lymphocytes and scattered Langhans type of giant cells was noted.

INFLAMMATORY CHANGES

Architectural alteration and chronic inflammation were noted. Chronic inflammation involving the full thickness of the mucosa was further classified as diffuse when all biopsy specimens from a particular site were diffusely involved, and as discontinuous when they were involved only in part. Focally enhanced colitis was defined as focal infiltration and overrunning of crypts by neutrophils, associated with increased mononuclear cells in the adjacent lamina propria, not involving the full thickness of the mucosa. Focal cryptitis and crypt abscess formation without the associated mononuclear infiltrate was termed focal activity. Where submucosal tissue was present and the degree of submucosal inflammation exceeded that of the overlying and adjacent non-ulcerated mucosa, disproportionate submucosal inflammation was recorded.

The $\chi^{2}$ test and Fisher's exact probability test were used to test the significance of differences in frequency of the various histological parameters in Crohn's disease and TEC. The MannWhitney $U$ test was used to compare mean values of appropriate parameters in the two groups.

\section{Results}

CLINICAL AND ENDOSCOPIC FINDINGS

The age and sex distribution of patients with tuberculosis and Crohn's disease were similar, with the average age at onset of illness being 34 and 33.3 years respectively and the male: female ratio 1.86 and 1.5 respectively. The total duration of symptoms in patients with a diagnosis of Crohn's disease (31.7 (21) months) was longer than that of tuberculosis patients (16.4 (21) months). Endoscopically, the distribution of macroscopic lesions was similar in the two conditions with $60-70 \%$ of patients showing ileocaecal involvement, and about $50 \%$ showing involvement of the transverse or distal colon. Involvement of the ileocaecal valve, deformity of the caecum, and stricture/stenosis were however more common in the tuberculosis patients, while fistulae were more in patients with Crohn's disease.

\section{HISTOLOGICAL FINDINGS}

Granulomas

Granulomas (fig 1), which were well defined organised collections of epithelioid histiocytes along with Langhans giant cells and many lymphocytes were found in all patients with TEC, but in only 11 of the 20 patients with Crohn's disease (table 1). These granulomas were identifiable in $46 \%$ of the 61 biopsy specimens from TEC but only in $14 \%$ of Crohn's disease specimens. If the specimen was from endoscopically abnormal tissue the yield was higher (table 1). In TEC biopsy specimens, the granulomas were large (mean widest diameter 193 (811) $\mu \mathrm{m}$, range $50-612.5 \mu \mathrm{m}$ ) with many larger than

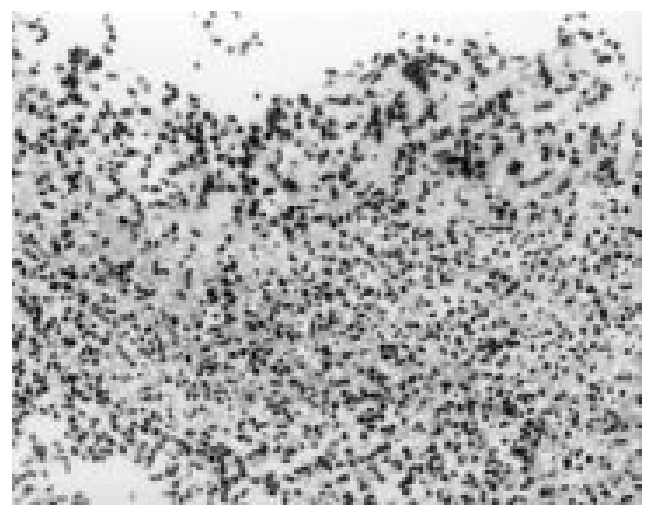

Figure 4 Mucosal biopsy of a patient with tuberculosis, showing a conglomerate band of epithelioid histiocytes at a site of ulceration. 


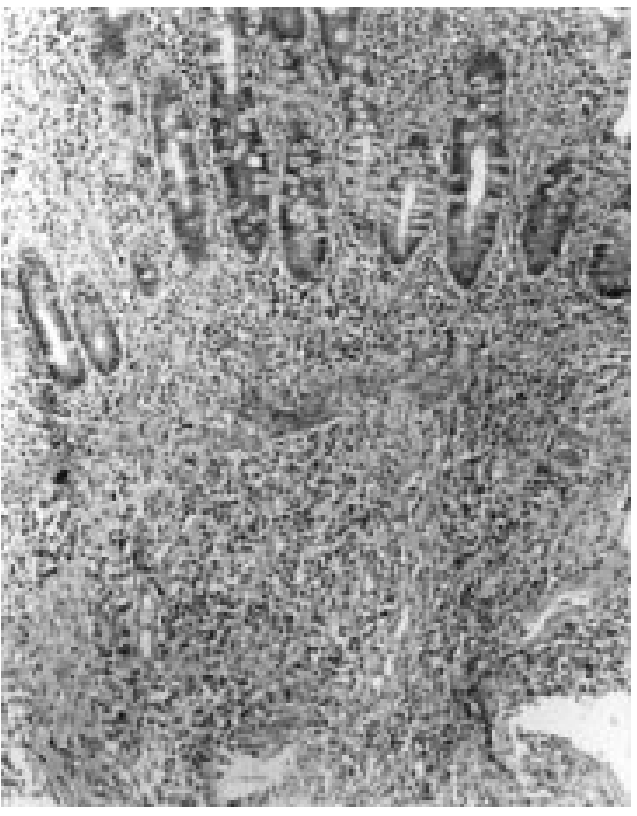

Figure 5 Ileal mucosal biopsy specimen from a patient with tuberculosis, showing disproportionate submucosal inflammation.

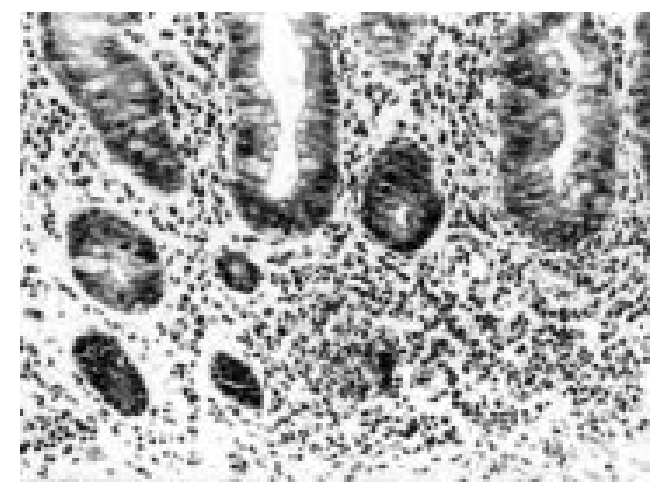

Figure 6 Colonic mucosal biopsy specimen of a patient with Crohn's disease, showing focal overrunning of crypts by neutrophils associated with increased chronic inflammatory cells in the adjacent lamina propria (focally enhanced colitis).

$200 \mu \mathrm{m}$ in diameter (fig $1 \mathrm{~A}$ ). In $40 \%$ of patients there was caseation, and confluence of granulomas in $60 \%$. In contrast, in Crohn's disease biopsy specimens the average size of granulomas was smaller (95 (499) $\mu \mathrm{m}$, range 50-250 $\mu \mathrm{m})$. Granulomas larger than $200 \mu \mathrm{m}$ were found in only one patient; average number of granulomas per section was less than one and there was no caseation or confluence (fig 1B). The percentage of granulomas located in the mucosa was similar in TEC and Crohn's disease, but in the submucosa and in the granulation tissue lining ulcers, they were significantly more frequent in TEC (table 1). These features of granulomas were analysed for the 20 patients from each group, for all biopsy sites in the two groups and separately for biopsy specimens from endoscopically abnormal and apparently normal appearing mucosa. Significant differences between TEC and Crohn's disease were consistently present (table 1).
Microgranulomas

Poorly organised collections of epithelioid histiocytes without the other features of granulomas (fig 2) were found in $40 \%$ of patients with Crohn's disease but in only one patient with TEC (table 1). These collections had an average diameter of 116 (154.5) $\mu \mathrm{m}$, range $62.5-662.5 \mu \mathrm{m}$ and were the same size as the granulomas found in patients with Crohn's disease. These microgranulomas were predominantly located in the mucosa and were not detected in the submucosa or in granulation tissue around ulcers.

\section{Ulcers}

Aphthoid ulcers were similar in prevalence but deep ulcers (fig 3) and ulcers lined by a band of epithelioid histiocytes (fig 4) were significantly more frequent in TEC (table 1).

\section{Chronic inflammatory changes}

Discontinuous areas of chronic inflammation were seen in both conditions (table 1) except in biopsy specimens from areas which were endoscopically normal. Seventy one per cent of specimens from endoscopically normal mucosa in Crohn's disease showed chronic inflammatory changes compared with only $11 \%$ in such specimens from TEC. Disproportionate chronic inflammatory change in the submucosa (fig 5) was significantly more in TEC (table 1) but not all specimens included submucosal tissue. Focally enhanced colitis was more common in Crohn's disease (fig 6).

\section{Discussion}

The analysis of a variety of histological changes in endoscopic mucosal biopsy specimens from clinically defined cases of TEC and Crohn's disease in a southern Indian patient group has clearly identified significant differences which enable differentiation of the two. TEC is characterised by numerous large, well defined granulomas, especially in the submucosa and in the granulation tissue around ulcers, often with caseation and confluence (table 1). The granulomas in Crohn's disease were fewer, smaller, never confluent or caseating, and seldom found in the submucosa.

Many of the reports of colonic tuberculosis have evaluated the histological changes in surgically resected specimens. ${ }^{13^{4} 17-19}$ We have earlier reported that in 40 of 50 patients the diagnosis of colonic tuberculosis could be confirmed by colonoscopic biopsy ${ }^{16}$ and others have also found colonoscopic biopsies useful in the diagnosis of TEC. ${ }^{20}$ The granulomas and other histological features of Crohn's disease have also been extensively described. ${ }^{2} 691121-23$ There are only a few reports, however, that compare the histological changes of Crohn's disease and TEC, ${ }^{12}{ }^{117}$ and all these authors have emphasised the diagnostic difficulties in distinguishing these two conditions, even with the availability of surgically resected specimens.

This retrospective, semiquantitative analysis of endoscopic biopsy specimens from clinically confirmed cases of Crohn's disease and TEC has enabled the characterisation of distinctive 
diagnostic features of these two disorders. The appearance of granulomas is a salient distinguishing feature as noted in this and previous studies. ${ }^{12417}$ The term microgranuloma ${ }^{14}$ was originally coined to describe small, poorly organised collections of histiocytes in Crohn's disease. Such collections were distinctly absent in all but one of the biopsy specimens of TEC and was found in eight of 20 patients with Crohn's disease in our study. The average size of the microgranulomas was the same as that of the classical Crohn's disease granulomas, although less than that of the granulomas in TEC. The presence of such microgranulomas in $10 \%$ of the biopsy specimens from endoscopically uninvolved mucosa along with chronic inflammatory changes in $71 \%$ of such sites (table 1) suggests that the disease process in Crohn's disease involves large areas of the intestine that may not manifest macroscopically. In contrast, TEC presents as areas of localised infection with a more severe granulomatous response, as evidenced by the larger, more frequent, confluent granulomas, often with caseating necrosis. The significantly higher prevalence of deep ulcers and disproportionate submucosal inflammation in TEC also suggest more intense disease activity than in Crohn's disease, although the latter parameter would need to be evaluated further in resected specimens as not all specimens included submucosal tissue.

Conventionally accepted histological features of Crohn's disease such as discontinuous mucosal inflammation ${ }^{68}$ and focal lesions ${ }^{9-11}$ were surprisingly also seen in the biopsy specimens of TEC. It is our suggestion that the term focally enhanced inflammation, defined as neutrophil infiltration and overrunning of crypts associated with a corresponding infiltrate of chronic inflammatory cells in the adjacent lamina propria, be more widely used for the typical focal lesions in Crohn's disease affecting the intestines. This will help to differentiate these lesions from other forms of focal activity that may be seen in TEC, other infections, ischaemic colitis, and partially treated ulcerative colitis. ${ }^{24}$ The term was originally used to describe the focal lesions of gastric mucosa affected by Crohn's disease, ${ }^{25}$ but our evaluation of colonic biopsy specimens showed similar lesions in the colonic mucosa of patients with Crohn's disease more frequently than in patients with TEC. They were unlike the isolated foci of activity characterised by cryptitis and crypt abscess formation without the associated mononuclear infiltrate (focal activity), that were seen in both conditions.

Among the 20 cases of Crohn's disease evaluated in our study, two were given antituberculous treatment prior to being classified as having Crohn's disease. One of them had had a biopsy prior to initiation of antituberculous treatment, which was initially diagnosed as consistent with TEC. On review this biopsy specimen showed only small granulomas and focally enhanced colitis, which in the light of our study, tipped the diagnosis towards Crohn's disease. Biopsies prior to treatment were not available for review on the other patient with Crohn's disease who was initially treated with antituberculous therapy, but tissue examined after partial therapy revealed microgranulomas, suggestive of Crohn's disease.

With the re-emergence of tuberculosis in the West in the wake of the AIDS epidemic, the ability to cure TEC with appropriate antibiotic treatment, and the emergence of Crohn's disease in many tropical countries where it was previously unknown, histological differentiation of these two disorders is of great importance. Although this is a retrospective study and the total number of patients studied is small, we feel that the histological features described here should enable the endoscopist and the gastrointestinal pathologist to play a greater role in arriving at a definitive diagnosis. Prospective studies and more extensive retrospective studies that include cases from the entire spectrum of disease, are however required to determine the usefulness of these parameters in indeterminate cases.

1 Hoon JR, Dockerty MB, Pemberton J. Ileocecal tuberculosis including a comparison of this disease with nonspecific regional enterocolitis and noncaseous tuberculated enterocolitis. International Abstracts of Surgery 1950;91:417-40.

2 Lee FD, Roy AD. Ileo-caecal granulomata. Gut 1964;5:51723.

3 Howell JS, Knapton PJ. Ileo-caecal tuberculosis. Gut 1964;5: $524-9$.

4 Tandon HD, Prakash A. Pathology of intestinal tuberculosis and its distinction from Crohn's disease. Gut 1972;13:260-9.

5 Shepherd NA. Pathological mimics of chronic inflammatory bowel disease. 7 Clin Pathol 1991;44:726-33.

6 Williams JW. Histology of Crohn's syndrome. Gut 1964;5: 510-16.

7 Dyer NH, Stansfeld AG, Dawson AM. The value of rectal biopsy in the diagnosis of Crohn's disease. Scand $\mathcal{F}$ Gastroenterol 1970;5:491-6.

8 Malatjalian DA. Pathology of inflammatory bowel disease in colorectal mucosal biopsies. Dig Dis Sci 1987;32 (suppl):5$15 \mathrm{~S}$.

9 Schmitz-Moormann P, Schag M. Histology of the lower intestinal tract in Crohn's disease of children and adolescents. Pathol Res Pract 1990;186:479-84.

10 Crohn BB, Ginzburg L, Oppenheimer GD. Regional ileitis: a pathological and clinical entity. $7 A M A 1932 ; 99: 1323-31$.

11 Cook MG, Dixon MF. An analysis of the reliability of detection and diagnostic value of various pathological features in Crohn's disease and ulcerative colitis. Gut 1973;14: tures in 62 .

12 Geboes K, Ectors N, D'Haens G, et al. Is ileoscopy with biopsy worthwhile in patients presenting with symptoms of inflammatory bowel disease? Am 7 Gastroenterol 1998;93: inflamm $201-6$.

13 Goldman $\mathrm{H}$. Interpretation of large intestinal mucosal biopsy specimens. Hum Pathol 1994;25:1150-9.

14 Rotterdam H, Sommers SC. Microgranulomas in grossly normal rectal mucosa in Crohn's disease. Am $\mathcal{F}$ Clin Pathol 1977;67:550-4.

15 Le Berre N, Heresbach D, Kerbaol M, et al. Histological discrimination of idiopathic inflammatory bowel disease from other types of colitis. F Clin Pathol 1995;48:749-53.

16 Shah S, Thomas V, Mathan M, et al. Colonoscopic study of 50 patients with colonic tuberculosis. Gut 1992;33:347-51.

17 Tonghua L, Guozong P, Minzhang C. Crohn's disease: clinicopathologic manifestations and differential diagnosis from enterocolonic tuberculosis. Chinese Med f 1981;94: 431-40.

18 Addison NV. Abdominal tuberculosis-a disease revived. Ann R Coll Surg Engl 1983;65:105-11.

19 Palmer KR, Patil DH, Basran GS, et al. Abdominal tuberculosis in urban Britain - a common disease. Gut 1985;26: 1296-305.

20 Bhargava DK, Tandon HD, Chawla TC, et al. Diagnosis of ileocecal and colonic tuberculosis by colonoscopy. Gastrointest Endosc 1985;31:68-70.

21 Chambers TJ, Morson BC. The granuloma in Crohn's disease. Gut 1979;20:269-74

22 Tanaka M, Riddell RH. The pathological diagnosis and differential diagnosis of Crohn's disease. Hepatogastroenterology 1990;37:18-31.

23 Lockhart-Mummery HE, Morson BC. Crohn's disease of the large intestine. Gut 1964;5:493-509.

24 Stern RA, Carpenter SL, Barnett JL, et al. The clinical significance of focal active colitis [abstract]. Gastoenterology 1995;108:A922.

25 Oberhuber G, Puspok A, Oesterreicher C, et al. Focally enhanced gastritis: a frequent type of gastritis in patients with Crohn's disease. Gastroenterology 1997;112:698-706. 